\title{
Integration of Physical, Genetic, and Cytogenetic Mapping Data for Cellulose Synthase (CesA) Genes in Flax (Linum usitatissimum L.)
}

\author{
Olga Y. Yurkevich ${ }^{1 \dagger}$, Ilya V. Kirov ${ }^{2 \dagger}$, Nadezhda L. Bolsheva ${ }^{1}$, Olga A. Rachinskaya', \\ Zoya E. Grushetskaya ${ }^{3}$, Svyatoslav A. Zoschuk ${ }^{1}$, Tatiana E. Samatadze1, \\ Marina V. Bogdanova ${ }^{3}$, Valentina A. Lemesh ${ }^{3}$, Alexandra V. Amosova ${ }^{1 *}$ and \\ Olga V. Muravenko ${ }^{1}$
}

'Engelhardt Institute of Molecular Biology, Russian Academy of Sciences, Moscow, Russia, ${ }^{2}$ Shemyakin-Ovchinnikov Institute of Bioorganic Chemistry, Russian Academy of Sciences, Moscow, Russia, ${ }^{3}$ Institute of Genetics and Cytology, National Academy of Sciences of Belarus, Minsk, Belarus

OPEN ACCESS

Edited by:

Chengdao Li,

Murdoch University, Australia

Reviewed by:

Liezhao Liu,

Southwest University, China

Sònia Garcia,

Consejo Superior de Investigaciones

Cientificas (CSIC), Spain

${ }^{*}$ Correspondence:

Alexandra V. Amosova

amomar@mail.ru

tThese authors have contributed equally to this work.

Specialty section:

This article was submitted to Crop Science and Horticulture, a section of the journal

Frontiers in Plant Science

Received: 18 June 2017 Accepted: 07 August 2017

Published: 23 August 2017

Citation:

Yurkevich OY, Kirov IV, Bolsheva NL, Rachinskaya OA, Grushetskaya ZE, Zoschuk SA, Samatadze TE, Bogdanova MV, Lemesh VA, Amosova AV and Muravenko OV

(2017) Integration of Physical, Genetic, and Cytogenetic Mapping Data for Cellulose Synthase (CesA) Genes in Flax (Linum usitatissimum

L.). Front. Plant Sci. 8:1467. doi: 10.3389/fpls.2017.01467
Flax, Linum usitatissimum L., is a valuable multi-purpose plant, and currently, its genome is being extensively investigated. Nevertheless, mapping of genes in flax genome is still remaining a challenging task. The cellulose synthase (CesA) multigene family involving in the process of cellulose synthesis is especially important for metabolism of this fiber crop. For the first time, fluorescent in situ hybridization (FISH)-based chromosomal localization of the CesA conserved fragment (KF011584.1), 5S, and 26S rRNA genes was performed in landrace, oilseed, and fiber varieties of $L$. usitatissimum. Intraspecific polymorphism in chromosomal distribution of KF011584.1 and 5S DNA loci was revealed, and the generalized chromosome ideogram was constructed. Using BLAST analysis, available data on physical/genetic mapping and also whole-genome sequencing of flax, localization of KF011584.1, 45S, and 5S rRNA sequences on genomic scaffolds, and their anchoring to the genetic map were conducted. The alignment of the results of FISH and BLAST analyses indicated that KF011584.1 fragment revealed on chromosome 3 could be anchored to linkage group (LG) 11. The common LG for 45S and 5S rDNA was not found probably due to the polymorphic localization of $5 S$ rDNA on chromosome 1. Our findings indicate the complexity of integration of physical, genetic, and cytogenetic mapping data for multicopy gene families in plants. Nevertheless, the obtained results can be useful for future progress in constructing of integrated physical/genetic/cytological maps in L. usitatissimum which are essential for flax breeding.

Keywords: gene mapping Linum usitatissimum L., genome, chromosome, CesA genes, BLAST analyses, FISH, rDNA

\section{INTRODUCTION}

Cultivated flax (Linum usitatissimum L., $2 n=2 x=30$ ) is an annual self-pollinated crop widely grown for use in food production, industry, and medicine. Currently, the genome of this valuable multi-purpose plant is being extensively investigated. The genome size of L. usitatissimum cultivar (cv.) CDC Bethune was estimated at $\sim 373 \mathrm{Mb}$ based on flow cytometry and draft sequencing of this 
genome was performed (Wang et al., 2012). A genetic map of flax based on SSR- and SNP-markers, five genes from the fatty acid biosynthesis pathway ( $f a d 2 A, f a d 2 B, f a d 3 A, f a d 3 B$, and dgat 1 ) and a phenotypic trait (seed coat color), was created (Cloutier et al., 2011). Also, a physical map of the genome of the flax cv. CDC Bethune, which consisted of 416 fingerprinted contigs spanning almost $100 \%$ of its genome, was developed (Ragupathy et al., 2011). Besides, genetic maps of three flax populations (CDC Bethune/Macbeth, E1747/Viking, and SP2047/UGG55) containing between 385 and 469 mapped markers were constructed (Cloutier et al., 2012). According to the linkage groups (LGs), consensus genetic and physical maps of flax were created (Cloutier et al., 2012; Kumar et al., 2015). However, this map has not been correlated to flax cytogenetic mapping developed earlier (Muravenko et al., 2003, 2009; Rachinskaya et al., 2011), and chromosomal localization of individual genes is still unexplored. Incorporation of physical, genetic, and cytological maps in one integrated map of the genome of L. usitatissimum is particularly important for investigation of genetic peculiarities of this valuable plant and further progress in flax breeding. Among all methods of physical mapping, only molecular cytogenetic techniques, such as fluorescent in situ hybridization (FISH), allow specific DNA sequences to be directly localized on mitotic and meiotic chromosomes. In this context, it can help their association with the LGs of genetic maps. For that purpose, highly conserved genes are usually mapped, and among these are cellulose synthase (Ces $A)$ genes of plants.

The complex multigene family of highly conserved Ces $A$ genes is believed to encode the glycosyltransferase enzymes which are involved in the process of cellulose synthesis in plants and play a significant role in gelatinous cell wall formation (Kawagoe and Delmer, 1997; Delmer, 1999; Robert et al., 2004; Taylor et al., 2004; Saxena and Brown, 2005). High expression levels of Ces $A$ genes observed in fast growing tissues of L. usitatissimum indicate that these genes are particularly important for this fiber crop (Gorshkova et al., 2005; Chantreau et al., 2015). Recently, 16 predicted CesA genes of flax were aligned with the welldefined CesA genes of Arabidopsis and Populus (Mokshina et al., 2014). All proteins encoded by CesAs genes include two plants conserved regions: P-CR1 and P-CR2 (Delmer, 1999; Richmond, 2000; Saxena et al., 2001; Doblin et al., 2002; Kumar and Turner, 2015; Kaur et al., 2016). The CesA genes can be identified by the P-CR sequence which is highly conserved in all plant CesAs (Doblin et al., 2002; Kumar and Turner, 2015; Kaur et al., 2016). Based on comparative studies of the nucleotide sequences of six flax CesA EST subunits (GenBank: EF409998-EF410000, EF214742-EF214744), the primers amplifying the 301 bp cDNA fragment of CesA-6 subunit (GenBank: KF011584.1) were designed (Grushetskaya et al., 2010). The alignment of the nucleotide sequence of the amplified CesA-6 fragment with the known sequences of the CesA genes of Arabidopsis, Populus, and Eucalyptus showed that the obtained KF011584.1 fragment comprised the region of the conserved P-CR2 domain of the CesA genes (Richmond and Somerville, 2000; Liang and Joshi, 2004; Ranik and Myburg, 2006).

In the present work, FISH-based chromosomal localization of the Ces $A$ conserved fragment (KF011584.1), 26S, and 5S rRNA genes was performed in karyotypes of one landrace, one oilseed, and two fiber varieties of L. usitatissimum. Using BLAST analysis, localization of KF011584.1, 45S, and 5S rRNA sequences on genomic scaffolds and their anchoring to the genetic map was conducted to align the obtained FISH results with the available data on physical/genetic mapping and whole-genome sequencing of flax.

\section{MATERIALS AND METHODS}

\section{Plant Material}

Four L. usitatissimum varieties were studied: Braginskij kryazh (landrace), LM-98 (oilseed), Slavnyj-82 (fiber), and Belita (fiber). The seeds of Braginskij kryazh and LM-98 were obtained from the germplasm collection of All-Russian Flax Institute, Torzok, Russian Federation; the seeds of Slavnyj-82 and Belita were obtained from the collection of the Institute of Genetics and Cytology, National Academy of Sciences of Belarus, Minsk, Belarus.

\section{Chromosome Slide Preparation}

For FISH, the modified technique of chromosome spread preparation from flax root tips was applied. The seeds were germinated in Petri dishes on moist filter paper at room temperature. Root tips (of $0.5 \mathrm{~cm}$ ) were excised and treated overnight (16-20 h) in ice-cold water with $1 \mu \mathrm{g} / \mathrm{ml}$ 9aminoacridine (Sigma, St. Louis, MO, United States) to harvest elongated chromosomes (Muravenko et al., 2003). After the pretreatment, the root tips were fixed in ethanol:acetic acid $(3: 1)$ for 3-24 h at room temperature. Before squashing, the roots were transferred into $1 \%$ acetocarmine solution in $45 \%$ acetic acid for $15 \mathrm{~min}$. The cover slips were removed after freezing in liquid nitrogen. The slides were dehydrated in $96 \%$ ethanol and then air dried.

\section{DNA Probe Preparation}

26S and 5S rDNA probes were isolated from genomic DNA of L. austriacum as described previously (Yurkevich et al., 2013). The rDNA probes were labeled directly with SpectrumAqua (26S rDNA) and SpectrumRed (5S rDNA) fluorochromes (Abbott Molecular, Wiesbaden, Germany) according to the manufacturer's protocol.

Fragments of the conserved domain B of the CesA-6 subunit (GenBank: KF011584.1) were obtained from cDNA of L. usitatissimum by PCR with primers F_À6_302: 5' TTATTGCTGTCCAGAGAGAG-3' and R_A6_302: 5'-AGAACC ATATACTGGCAAGA-3' developed previously (Grushetskaya et al., 2010). These DNA fragments were cloned using pGEMT Easy Vector System (Promega, Madison, WI, United States) in competent Escherichia coli cells of DHSa strain and isolated by the Plasmid DNA Isolation kit (Evrogen, Moscow, Russian Federation) according to the manufacturer's protocols. Then, the cloned fragments were sequenced using Applied Biosystems 3730 DNA Analyzer and then labeled by Fluorescein Labeling Kit (MirusBio, Madison, WI, United States) according to the manufacturer's protocols. Four microliters of $10 \mathrm{mg} / \mathrm{ml}$ sonicated 
salmon sperm DNA (Gibco BRL, New York, NY, United States) was added to each labeled probe mix which was precipitated with $100 \%$ ethanol and dissolved in $50 \mu \mathrm{l}$ hybridization solution (50\% deionised formamide, 10\% dextran sulfate, 1\% Tween-20, and $2 \times$ SSC). The concentration of the final DNA fragment was $\geq 20$ (ng/ $\mu \mathrm{l})$. The probes were stored at $-20^{\circ} \mathrm{C}$ before use.

\section{FISH Procedure}

Before FISH procedure, chromosome slides were pre-treated with $1 \mathrm{mg} / \mathrm{ml}$ RNase A (Roche) in $2 \times \mathrm{SSC}$ at $37^{\circ} \mathrm{C}$ for $1 \mathrm{~h}$ and then washed three times for $10 \mathrm{~min}$ in $2 \times \mathrm{SSC}$. The slides were dehydrated in a series of 70,85 , and $96 \%$ ethanol solutions and then air dried. The hybridization mixture $(15 \mu \mathrm{l})$ containing $40 \mathrm{ng}$ of each labeled probe was added to each slide. Coverslips were placed on the slides and sealed with rubber cement. Slides with DNA probes were co-denatured at $74^{\circ} \tilde{\mathrm{N}}$ for $5 \mathrm{~min}$, placed in a moisture chamber, and hybridized overnight at $37^{\circ} \mathrm{C}$. After removing the coverslips, the slides were washed twice with $0.1 \times$ SSC at $44^{\circ} \mathrm{C}$ for $10 \mathrm{~min}$, followed by two washes with $2 \times$ SSC at $44^{\circ} \mathrm{C}$ for $5 \mathrm{~min}$ and the final $5 \mathrm{~min}$ wash in $2 \times$ SSC at room temperature. Prior to detection, the slides were soaked in $4 \times \operatorname{SSCT}(0.1 \%$ Tween-20 in $4 \times$ SSC) at room temperature for $3 \mathrm{~min}$ and then incubated in a detecting buffer (5\% fatfree dry milk in $4 \times \mathrm{SSCT}$ ) at $37^{\circ} \mathrm{C}$ for $30 \mathrm{~min}$. The slides were washed in $4 \times$ SSCT at room temperature for $3 \mathrm{~min}$. In the case of the conserved domain B the CesA-6 subunit was labeled directly by Fluorescein Labeling Kit (Kreatech Biotechnology, Amsterdam, Netherlands), the fluorescent signal amplification using FITC-Alexa 488 antibodies (VectorLabs, Youngstown, $\mathrm{OH}$, United States) was performed.

After incubation for $60 \mathrm{~min}$ at $37^{\circ} \mathrm{C}$ with the detection mixture, the slides were washed three times with $4 \times$ SSCT for 3 min each at room temperature, followed by a short rinse in PBS. The slides were dehydrated and air dried in the dark.

\section{DAPI-Banding}

After FISH procedure, the slides were stained with $0.125 \mu \mathrm{g} / \mathrm{ml}$ 4',6-diamidino-2-phenylindole (DAPI) (Serva, Heidelberg, Germany) dissolved in Citifluor anti-fade solution (UKC Chem. Lab., Canterbury, United Kingdom).

\section{Chromosome Analysis}

Metaphase chromosome spreads were selected for analysis in accordance with the principles previously defined for small-sized chromosomes (Popov et al., 2001). In karyotypes, chromosomes were identified according to the cytological classification of L. usitatissimum developed previously (Muravenko et al., 2009). The slides were examined using an Olympus BX61 epifluorescence microscope (Olympus, Tokyo, Japan). Images were captured with monochrome charge-coupled device camera (Cool Snap, Roper Scientific, Inc., Sarasota, FL, United States). Then they were processed with Adobe Photoshop 10.0 software (Adobe, Birmingham, AL, United States). At least 15 metaphase plates were investigated for each specimen.

\section{Localization of CesA, 26S, and 5S rRNA Genes on Genomic Scaffolds and Their Anchoring to the Genetic Map}

To integrate obtained FISH results with the whole-genome sequencing data, BLAST analysis with 5S (X59854.1), 26S (EU307117.1) rDNA, and KF011584.1 sequences was performed against L. usitatissimum scaffolds ${ }^{1}$. All scaffolds with significant similarity $(1 e-5)$ to the query sequences were selected. To anchor these scaffolds with the LGs established by Cloutier et al. (2012), BLAST analysis with primer pairs used for the linkage map construction was performed against these flax scaffolds.

\section{RESULTS}

\section{DAPI-Banding and FISH with $26 \mathrm{~S}$ and 5 S rDNA for Chromosomal Identification of the Studied L. usitatissimum Varieties}

The karyotypes of all studied varieties consisted of 30 smallsized metacentric chromosomes (1-3 $\mu \mathrm{m})$. DAPI-banding patterns of the karyotypes were chromosome-specific and mostly represented by large heterochromatic bands found in the pericentromeric regions and small bands detected in the telomeric and/or intercalary regions of the chromosomes (Figures 1, 2). DAPI-banding patterns allowed us to identify the homologous chromosome pairs in all studied karyotypes. In accordance with the cytological classification of chromosomes developed previously (Muravenko et al., 2009), the generalized idiogram of chromosomes of the studied L. usitatissimum varieties with account of all possibilities of DAPI-banding patterns, FISH-based localization of 26S, 5S rDNA, and CesA genes was constructed (Figure 3).

Fluorescent in situ hybridization analysis showed similar distribution of 26S rDNA sites in all studied varieties (Figure 1). One polymorphic (in size) 26S rDNA site was detected in the secondary constriction region of the satellite chromosome 1 (according to the cytological classification) involving the adjusting chromosomal areas (detailed in Figure 1). 5S rDNA loci were revealed in the proximal part of the long arm of chromosomes 3 (3L1.3) and 8 (8L1.3) as well as in the distal end of the short arm of chromosome 13 (13S1.3) in karyotypes of the studied varieties. In some plants of Braginskij kryazh variety, one small polymorphic 5S rDNA site (co-localized with $26 \mathrm{~S}$ rDNA site) was observed on chromosome 1 (Figure 1).

\section{FISH Mapping of the CesA Gene Fragment}

Localization of the conserved Ces $A$ gene sequence on metaphase chromosomes of the studied L. usitatissimum varieties was performed by FISH with the amplified CesA-6 fragment (KF011584.1) as a DNA probe (Figures 2, 3). In three varieties LM-98, Slavnyj-82, and Belita, sites of hybridization of the CesA genes were mapped on both arms of chromosomes 2 and also on

\footnotetext{
${ }^{1}$ http://www.phytozome.net
} 
A
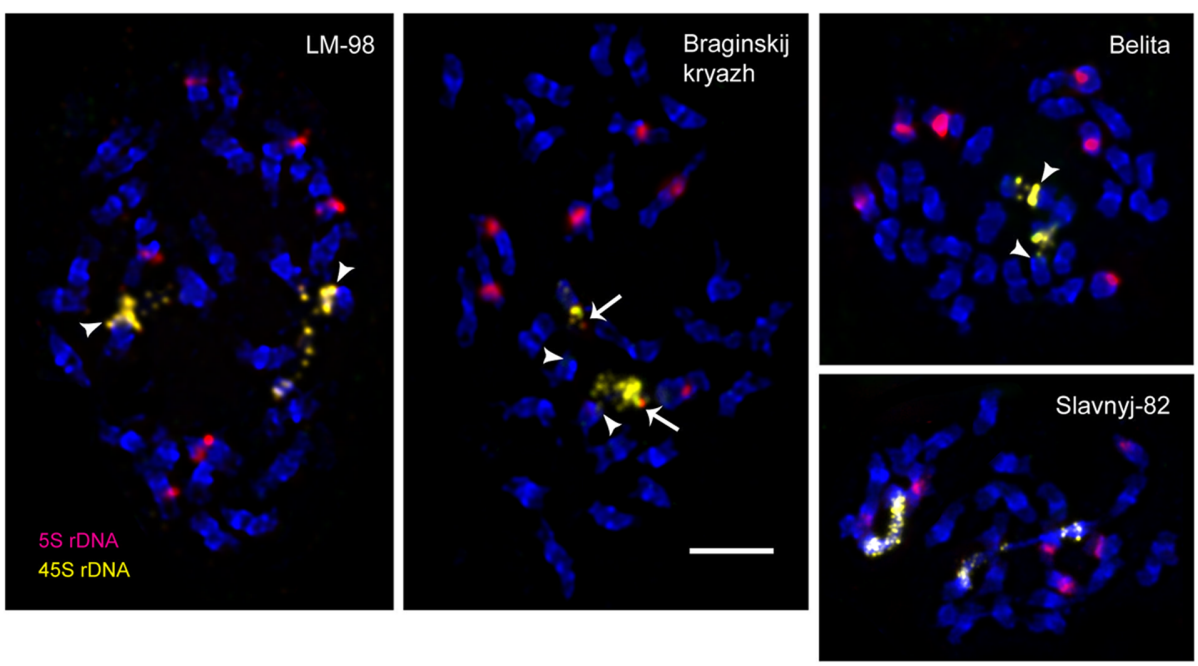

B

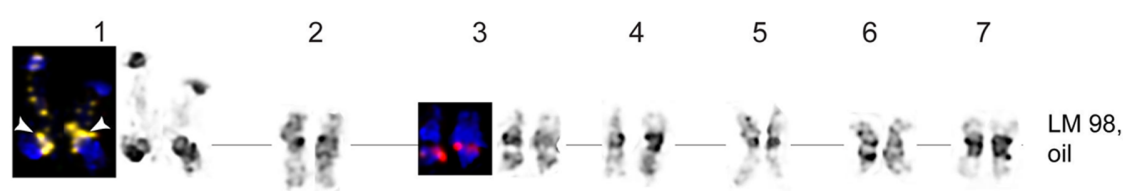

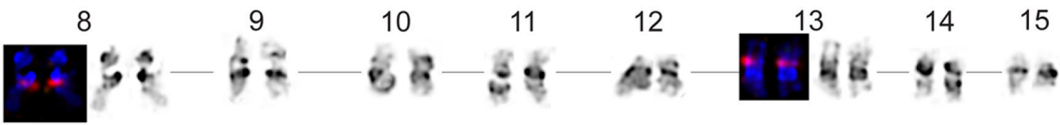

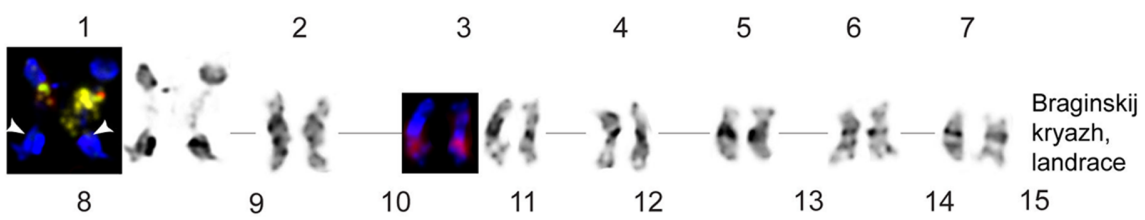

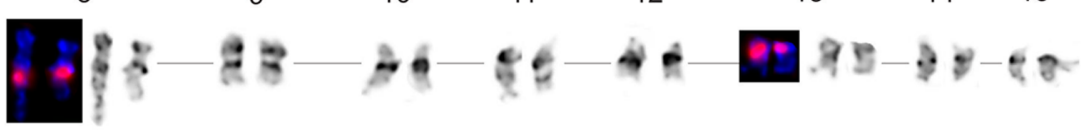

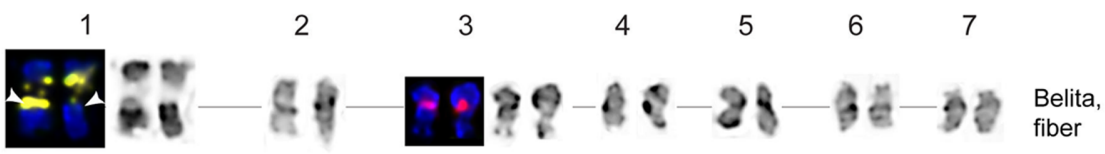

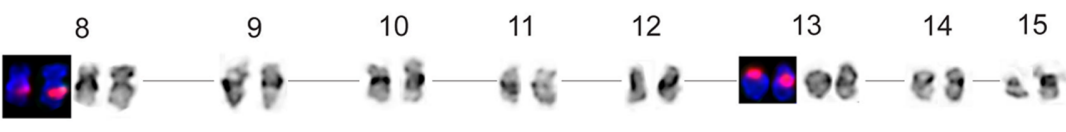

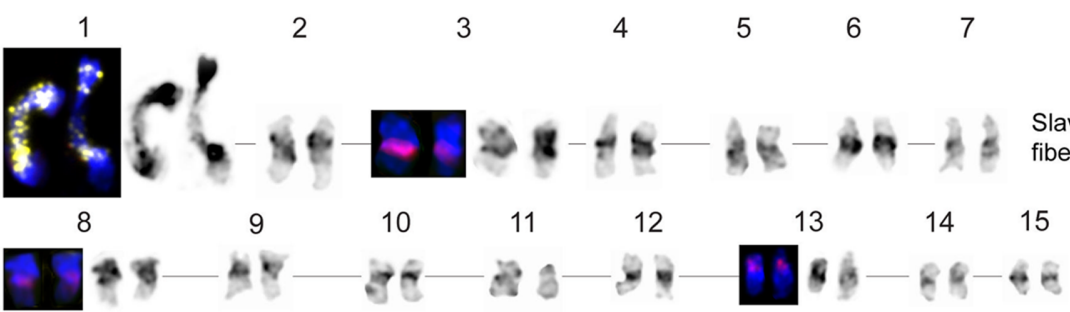

FIGURE 1 | FISH-based localization of $26 \mathrm{~S}$ (yellow) and 5 S (red) rDNA on chromosomes of the studied L. usitatissimum varieties. (A) Metaphase spreads of LM-98 (oilseed), Braginskij kryazh (landrace), Belita (fiber), and Slavnyj-82 (fiber) after FISH; (B) karyograms [the same metaphase plates as in (A)] of these varieties after DAPI-banding (inverted image) and FISH (only chromosomes with the hybridizations sites are presented). The heads of arrows point to the polymorphic $26 \mathrm{~S}$ rDNA sites (yellow) on satellite chromosome 1. The arrows point to the polymorphic 5S rDNA sites (red) on satellite chromosome 1. Bar $-5 \mu \mathrm{m}$. 
A
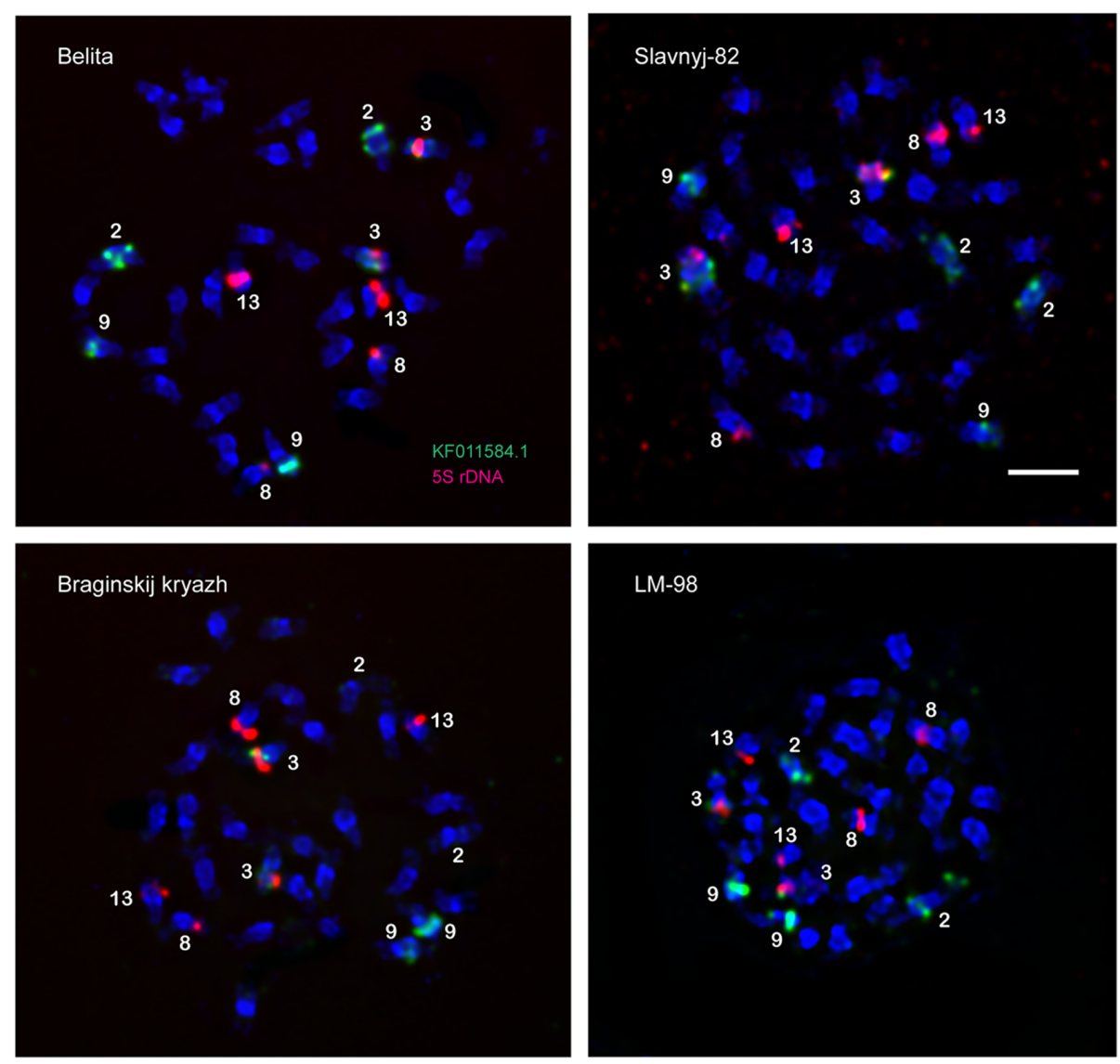

B 2 3 8 9 13

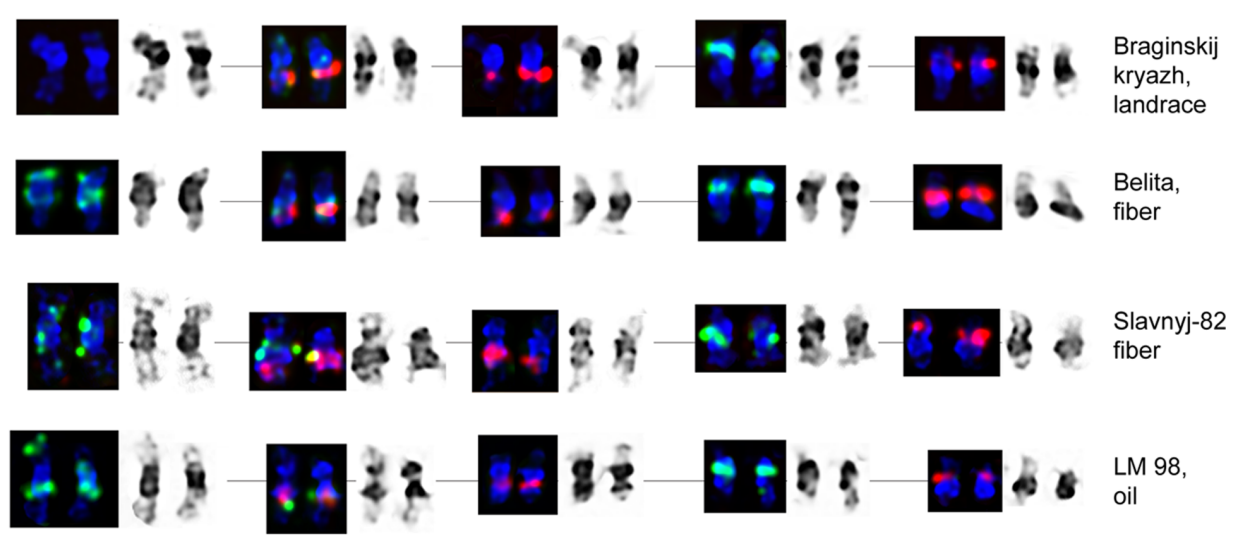

FIGURE 2 | FISH-based localization of $5 S$ (red) rDNA and the plant-conserved fragment (KF011584.1) of CesA genes (green) on chromosomes of $L$. usitatissimum varieties Belita, Slavnyj-82, Braginskij kryazh, and LM-98. (A) Metaphase spreads of Belita (fiber) Slavnyj-82 (fiber), Braginskij kryazh (landrace), and LM-98 (oilseed) after FISH; (B) the karyograms [the same metaphase plates as in (A)] after DAPI-banding (inverted image) and FISH (only chromosomes with the hybridizations sites are presented). Bar $-5 \mu \mathrm{m}$.

chromosomes 3 and 9, but in Braginskij kryazh, sites of the CesA genes were revealed only on chromosomes 3 and 9 (Figure 2).

In chromosome 2 , the polymorphic hybridization sites were localized in the distal end of the short arm (region 2S1.3) and in the proximal part of the long arm (region 2L1.3). In chromosome 3 , the hybridization sites were mapped in region $3 \mathrm{~L} 1.2$ of the long arm and also between the centromere and the region of localization of $5 \mathrm{~S}$ rDNA site. In chromosome 9 , bright 


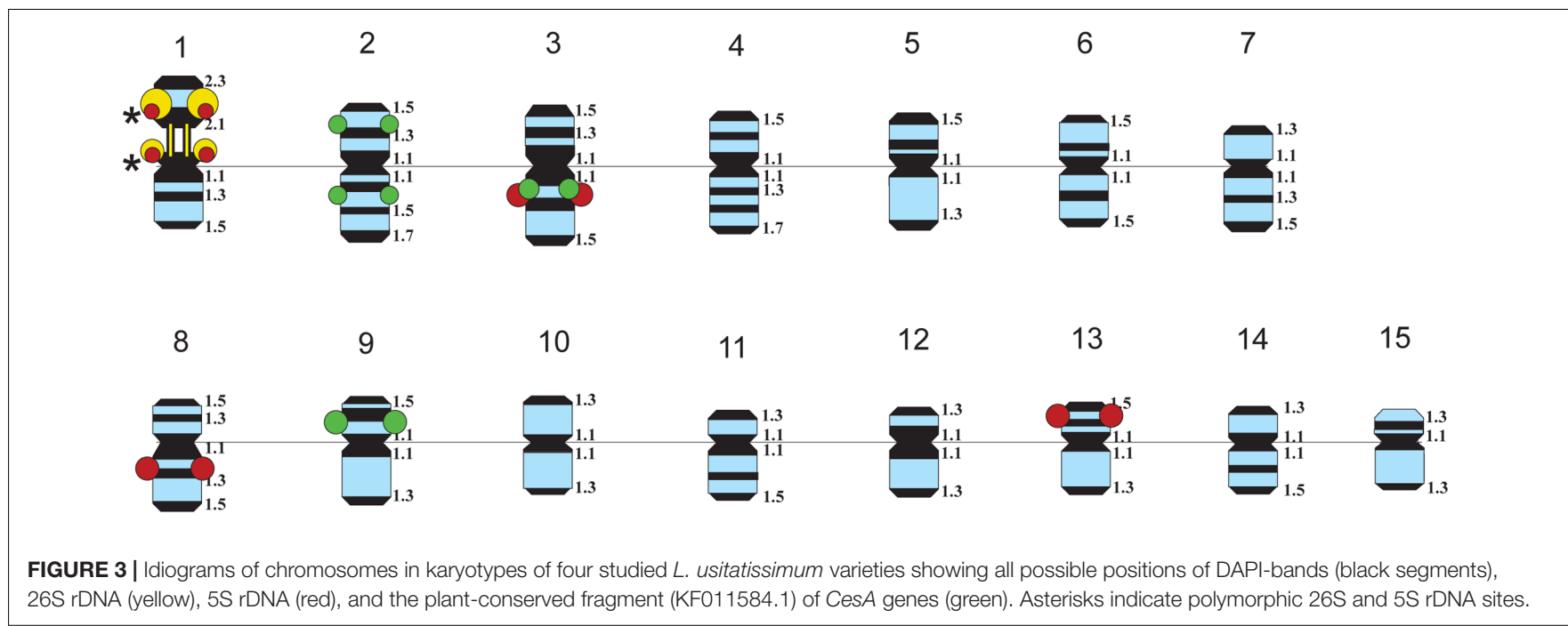

TABLE 1 | Scaffolds with similarity to KF011584.1 anchored to the linkage groups (LGs) by markers.

\begin{tabular}{|c|c|c|c|c|c|c|c|}
\hline$n / n$ & $\begin{array}{l}\text { Scaffold } \\
\text { name }\end{array}$ & $\begin{array}{l}\text { Contig length } \\
\text { (bp) }\end{array}$ & $\begin{array}{l}\text { Similarity to the FISH } \\
\text { probe sequence }\end{array}$ & LG & $\begin{array}{l}\text { Markers for anchoring of } \\
\text { scaffolds to LGs }\end{array}$ & Position (cM) & $\begin{array}{l}\text { Relative position on LG (\%) } \\
\text { Position * 100/LG length }\end{array}$ \\
\hline 1 & scaffold157 & 330988 & $99.3 \% ; 299 / 301$ & 1 & Lu3231 & 130.76 & 76.9 \\
\hline 2 & scaffold1099 & 165476 & 98.9\%; 299/301 & 1 & Lu3231 & 130.76 & 76.9 \\
\hline 3 & scaffold103 & 720360 & $70.3 \% ; 128 / 239$ & 1 & Lu2687 & 136.8 & 80.4 \\
\hline 4 & scaffold259 & 306757 & $73.6 \% ; 198 / 269$ & 9 & Lu2168 & 64 & 67.7 \\
\hline \multirow[t]{3}{*}{5} & scaffold57 & 1820724 & $72.4 \% ; 176 / 243$ & 11 & lu512 & 55.1 & 64 \\
\hline & & & & 11 & Lu785R224 & 55.8 & 65 \\
\hline & & & & 11 & Lu3078 & 59 & 68.5 \\
\hline \multirow[t]{3}{*}{6} & scaffold38 & 872253 & 74\%; 199/269 & 14 & Lu3043 & 17.6 & 23.14 \\
\hline & & & & 14 & Lu3033 & 26.7 & 35.1 \\
\hline & & & & 14 & Lu3046 & 27.85 & 36.6 \\
\hline \multirow[t]{2}{*}{7} & scaffold360 & 1176022 & $74.8 \% ; 190 / 254$ & 15 & Lu2695 & 52.46 & 87.6 \\
\hline & & & & 15 & Lu2697 & 59.9 & 100 \\
\hline 8 & scaffold1376 & 440504 & $74.6 \% ; 153 / 205$ & 15 & lu1007 & 46 & 76.8 \\
\hline \multirow[t]{7}{*}{9} & scaffold280 & 2404031 & $70.6 \% ; 173 / 245$ & 15 & lu271 & 6.3 & 42865 \\
\hline & & & & 15 & Lu2931 & 7 & 42927 \\
\hline & & & & 15 & lu510 & 8.7 & 42869 \\
\hline & & & & 15 & Lu3186 & 11.9 & 20 \\
\hline & & & & 15 & Lu3026 & 13.5 & 42877 \\
\hline & & & & 15 & Lu3185 & 17.3 & 42975 \\
\hline & & & & 15 & lu1163 & 22.2 & 37 \\
\hline
\end{tabular}

hybridization signals were detected in the median part of the short arm (9S1.2) (Figures 2, 3).

\section{Anchoring of the CesA Genes to the Linkage Groups}

Twenty-nine scaffolds and contigs with the length range from 109 to $2404031 \mathrm{bp}$ showed similarity to the query sequence $(E$-value $=1 \mathrm{e}-5$; coverage $>30 \%$; identity $>50)$. Two scaffolds (157 and 1099) demonstrated the highest similarity (>98\%) and query coverage $(100 \%)$ while the other scaffolds showed lower similarity $(<75 \%)$ and query coverage $(<90 \%)$. To anchor these scaffolds to the LGs established by Cloutier et al. (2012), BLAST analysis with the primer pairs, used for the linkage map construction, was performed against the flax scaffolds. Nine of twenty-nine CesA possessing scaffolds could be anchored to the LGs by one to seven markers (Table 1). For some scaffolds (1186, 280, and 464), the markers belonged to different LGs indicating possible scaffold misassembles, errors in genetic mapping, or genome duplication regions. It was not possible to assign scaffolds 1186 and 464 to certain LG because markers were shared by different LGs. Nine anchored scaffolds were distributed along five LGs $(1,9,11,14$, and 15). Based on the similarity, two top scaffolds (157 and 1099) were identical.

For further integration of physical and genetic mapping, scaffolds carrying rRNA genes were identified by BLAST analysis 


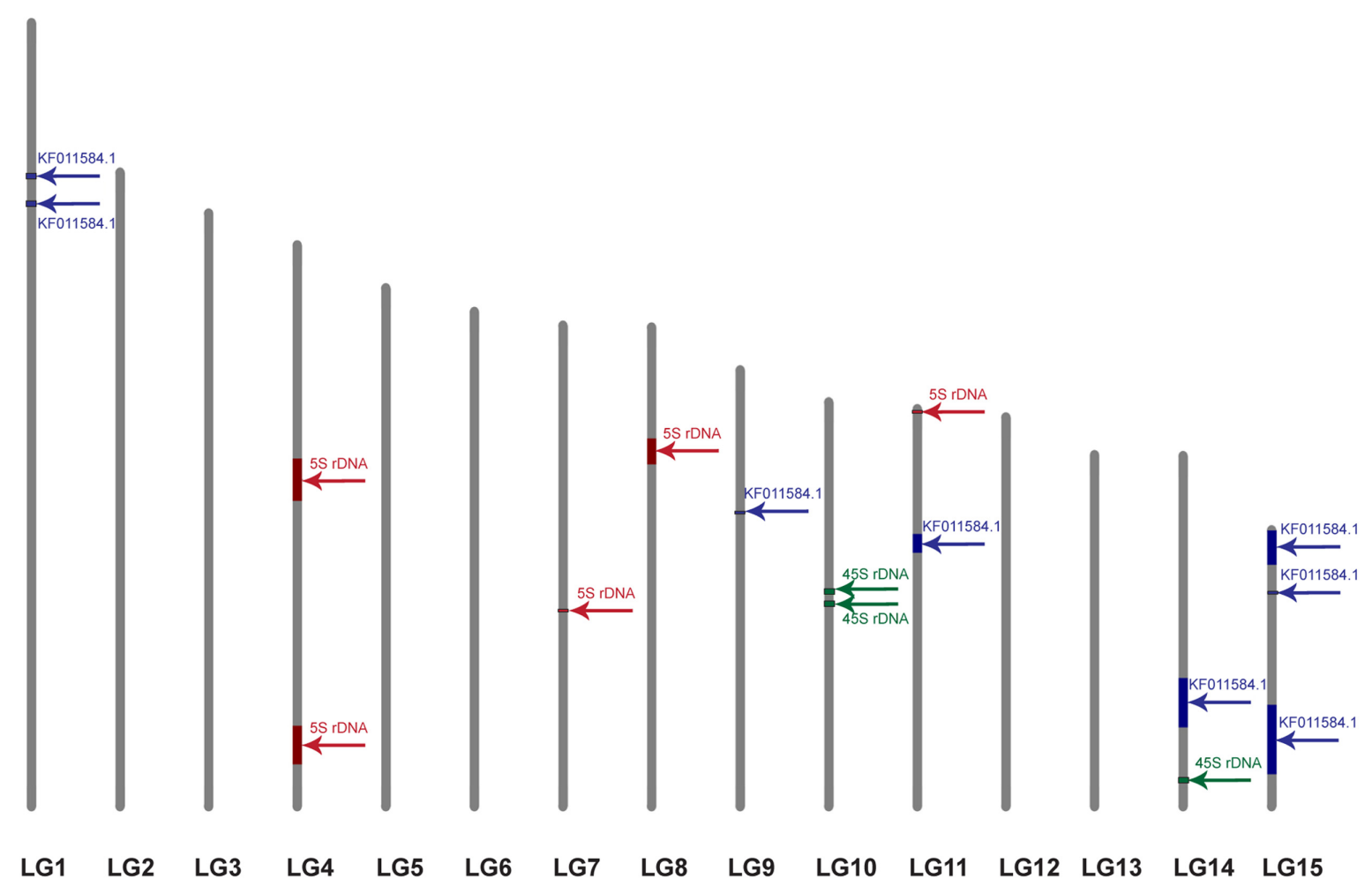

FIGURE 4 | Localization of the scaffolds carrying 5S rDNA (red), 45S rDNA (green), and the plant-conserved fragment (KF011584.1) of CesA genes (blue) on the genetic map of $L$. usitatissimum. The framework of the genetic map was published earlier (Cloutier et al., 2012). The size of the colored box corresponds to the portion of the linkage group occupied by the scaffolds, which was calculated through the minimum and maximum positions of the markers belonged to the scaffolds.

with 5S (X59854.1) and 45S (EU307117.1) rDNA sequences of L. usitatissimum. We found 7 and 365 scaffolds with similarity to the $45 \mathrm{~S}$ and $5 \mathrm{~S}$ rRNA genes, respectively. Ces $A$ containing scaffolds possessed rRNA genes were not revealed. Five and three scaffolds with $5 \mathrm{~S}$ and $45 \mathrm{~S} \mathrm{rDNA}$, respectively, were anchored to the genetic map by at least one marker (Figure 4). Five $5 \mathrm{~S}$ and three 45S rRNA gene contigs were located on four LGs $(4,7,8$, and 11) and two LGs (10 and 14), respectively.

\section{DISCUSSION}

The CesA multigene family encoding the glycosyltransferase enzymes plays a key role in the process of plant cellulose synthesis. These genes are especially important for bast fiber crops such as flax (L. usitatissimum) as the metabolism of fibers cells is oriented toward the extensive cellulose synthesis (Gorshkova et al., 2005; Chantreau et al., 2015). The problem of development of flax fibers is very important from a practical perspective because the elongation of the fiber cells as well as formation of the primary and secondary cell walls are directly associated with fiber quality, and also the yields of fiber flax varieties depend on the quantity and properties of fiber bundles (Gorshkova et al., 2005). The proteins encoded by plant CesAs genes are known to include two P-CRs (P-CR1 and P-CR2) CesAs which can be used for their identification
(Richmond, 2000; Kumar and Turner, 2015; Kaur et al., 2016).

In the present study, using one of the Ces $A$ conserved fragment (P-CR2) as a FISH probe allowed us to localize the $\tilde{N} a ̊ s \grave{A}$ genes on L. usitatissimum chromosomes. Interestingly, FISH analysis did not reveal any peculiarities in Ces $A$ gene localization on chromosomes of fiber flax compared to the other studied L. usitatissimum varieties. The hybridization sites of the P-CR2 fragment of CesA genes were found on three pairs of chromosomes (2, 3, and 9). However, the hybridization signals observed on both arms of chromosome 2 were polymorphic. They were not found in the karyotype of the studied landrace (Braginskij kryazh) variety probably due to intraspecific variability of the copy number of the Ces $A$ genes. Some CesA genes could not be localized in case they were presented in few copies due to rather low resolution of FISH method (Jiang and Gill, 2006; Lamb et al., 2007; Karafiátová et al., 2013; Danilova et al., 2014). Therefore, the revealed sites of the Ces $A$ genes were apparently presented in flax chromosomes as multiple closely located isoforms or tandemly arranged copies.

BLAST analysis on localization of KF011584.1, 45S, and 5S rRNA sequences on genomic scaffolds and their anchoring to the genetic map of L. usitatissimum based on the data of Cloutier et al. $(2011,2012)$ showed that the studied fragment of Ces $A$ genes was located in eight loci within five LGs $(1,9,11,14$, and 15). Genetic mapping studies of Arabidopsis, maize, and rice showed that the 
members of the CesA gene families were mostly spread across the genome although some genes were clustered together (Holland et al., 2000; Wang et al., 2010). Based on genetic mapping, CesA genes were detected in five barley chromosome pairs, in three Arabidopsis chromosome pairs, and in five maize chromosome pairs (Holland et al., 2000; Burton et al., 2004). CesA genes can be localized in one (shown for maize) or in both (in barley and wheat) chromosomal arms (Holland et al., 2000; Burton et al., 2004; Kaur et al., 2016). It has been shown that closely related Ces $A$ genes were often located in different chromosomes and the genes responsible for synthesis of the primary and secondary cell walls could be localized in one chromosomal region (Holland et al., 2000; Kaur et al., 2016). Unfortunately, the information on chromosome mapping of CesA genes is still rather limited, and we did not find any published studies on chromosome mapping of CesA genes in other plant species.

In the present work, 26S and 5S rRNA genes were used as chromosomal markers in FISH-based mapping of CesA genes. It is to be noted that polymorphism on distribution of $26 \mathrm{~S}$ and $5 \mathrm{~S}$ rRNA genes was previously described in karyotypes of different varieties of flax (Muravenko et al., 2003, 2009; Rachinskaya et al., 2011). We also detected polymorphism in distribution of $5 \mathrm{~S}$ rDNA loci in karyotype of the landrace variety Braginskij kryazh. It was early shown that the number of $45 \mathrm{~S}$ and $5 \mathrm{~S}$ rRNA genes could vary considerably in L. usitatissimum (Goldsbrough and Cullis, 1981; Goldsbrough et al., 1982; Schneeberger et al., 1989). Based on restriction fragment length polymorphism (RFLP) and Random Amplification of Polymorphic DNA (RAPD) analyses, one site of rRNA genes and a specific subset of 5S rRNA genes were localized in one LG (13F) of flax hybrid lines (Oh et al., 2000). However, the association of rDNA genes with the LGs is still controversial probably due to the difficulties in genetic mapping of the multigene families (Ragupathy et al., 2011).

In this study, we identified scaffolds possessing $45 \mathrm{~S}$ and $5 \mathrm{~S}$ rRNA genes and anchored them to the six $(4,7,8,10,11$, and 14) LGs according to the linkage map of flax (Cloutier et al., 2011, 2012). According to our results, three loci of $45 \mathrm{~S}$ rRNA genes were mapped within two LGs (10 and 14) though 26S rDNA sites were localized by FISH only in satellite chromosome 1. Also, five loci of 5S rDNA were mapped within four LGs (4, 7,8 , and 11). Considering the fact that $5 \mathrm{~S}$ rRNA genes were localized by FISH on chromosomes 1 (polymorphic), 3, 8, and 13 (cytological classification), these chromosomes could probably be associated with the established LGs (4, 7, 8, and 11). Besides, the common LG for $26 \mathrm{~S}$ and 5S rRNA genes was not found and this fact could be related to the intraspecific polymorphism in localization of $5 \mathrm{~S}$ rDNA on chromosome 1. Our results may suggest that either the sensitivity of FISH method has a limited value for detection of the short rDNA sequences or there is significant DNA polymorphism between the cultivars used for the sequencing and the ones studied in the present work. Because of multiple rDNA localization on L. usitatissimum chromosomes, it is not currently possible to anchor FISH signals to the bioinformatically established loci. However, the obtained results can be used in the future as an additional source of information to produce an integrated genetic/physical map for this species.
Fluorescent in situ hybridization analysis showed that the studied fragment of CesA genes and 5S rDNA was localized very closely to each other in chromosome 3 (cytological classification). Besides, the Ces $A$ conserved fragment and 5S rRNA genes were co-localized only in one LG (11). This allowed us to assume that the Ces $A$ genes revealed on chromosome 3 could be anchored to the LG 11. Apart from chromosome 3, the CesA fragment was also localized in two chromosome pairs by FISH. However, the CesA sequence (seven loci) was anchored in four LGs $(1,9,14$, and 15). The observed discrepancies in the copy number and distribution of the CesA conserved fragment and 5S rRNA genes on the genetic and physical cytological maps can be explained by several reasons. First, the flax varieties studied in the present work and the cultivars used for genome sequencing might have copy number variation (CNV) of Ces $A$ genes. The information on the extent and distribution of CNVs of different genes in plant genomes is rather limited. Copy number variations were found for 30\% of potato genes (Hardigan et al., 2016) and $10 \%$ of maize genes (Swanson-Wagner et al., 2010) as well as 2.2 Mb (2\%) of Arabidopsis thaliana genome (Cao et al., 2011). Besides, CNVs of different genes were shown to play a part in regulation of the processes of plant adaptation to environmental stress (Iovene et al., 2013; Hardigan et al., 2016). It was early reported that the genome of $L$. usitatissimum possessed some labile DNA sequences (including rRNA genes) which can vary within a single generation when the plants are grown under specific environmental conditions (Oh and Cullis, 2003; Cullis, 2005). Second, due to rather low sensitivity of FISH (about 300010000 bp) (Jiang and Gill, 2006; Lamb et al., 2007; Karafiátová et al., 2013; Danilova et al., 2014), the studied P-CR2 fragment of CesA genes cannot be possible to visualize on mitotic flax chromosomes in case if it is presented in one or several copies.

Fluorescent in situ hybridization-based cytogenetic maps were integrated with genetic maps for a number of cultivated species: rice (Chen et al., 2002), melon (Gonzalez et al., 2010), grapes (Scalabrin et al., 2010), maize (Wei et al., 2009), cotton (Cui et al., 2015), and Rosa wichurana (Kirov et al., 2014, 2016). In the present study, for the first time, chromosomal localization of the highly conserved fragment belonging to the Ces $A$ multigene family, 5S, and 26S rRNA genes was aligned to the integrated genetic/physical map of L. usitatissimum. For construction of the integrated map of flax, the increase in the number of new sequence-based molecular and chromosome markers is needed. Our findings show the complexity of integration of physical, genetic, and cytogenetic mapping data for multicopy gene families in plants. Nevertheless, integration of physical, genetic, and cytological maps is essential for flax breeding progress, and the obtained results can be useful for future progress in constructing such a map for L. usitatissimum.

\section{AUTHOR CONTRIBUTIONS}

The present study was conceived and designed by OM, OY, IK, and VL. OY, OR, ZG, NB, AA, SZ, TS, and MB performed the experiments. OY, OM, NB, VL, IK, OR, SZ, TS, AA, MB, and ZG analyzed the data; bioinformatics analysis was provided by IK. 
OY, OM, IK, VL, OR, ZG, NB, SZ, TS, MB, and AA participated in preparing and writing the manuscript. OM, OY, VL, AA, IK, ZG, $\mathrm{OR}, \mathrm{SZ}, \mathrm{TS}, \mathrm{MB}$, and NB performed the analysis with constructive discussions. All authors contributed to revising the manuscript. All authors have read and approved the final manuscript.

\section{FUNDING}

This work was financially supported by the Russian Foundation of Basic Research (Grant No. 16-04-01239) and also the Program

\section{REFERENCES}

Burton, R. A., Shirley, N. J., King, B. J., Harvey, A. J., and Fincher, G. B. (2004). The CesA gene family of barley. Quantitative analysis of transcripts reveals two groups of co-expressed genes. Plant Physiol. 134, 224-236. doi: 10.1104/pp.103. 032904

Cao, J., Schneeberger, K., Ossowski, S., Günther, T., Bender, S., Fitz, J., et al. (2011). Whole-genome sequencing of multiple Arabidopsis thaliana populations. Nat. Genet. 43, 956-963. doi: 10.1038/ng.911

Chantreau, M., Chabbert, B., Billiard, S., Hawkins, S., and Neutelings, G. (2015). Functional analyses of cellulose synthase genes in flax (Linum usitatissimum) by virus-induced gene silencing. Plant Biotechnol. J. 13, 1312-1324. doi: 10.1111/ pbi. 12350

Chen, M., Presting, G., Barbazuk, W. B., Goicoechea, J. L., Blackmon, B., Fang, G., et al. (2002). An integrated physical and genetic map of the rice genome. Plant Cell 14, 537-545. doi: 10.1105/tpc.010485

Cloutier, S., Ragupathy, R., Miranda, D. E., Radovanovic, N., Reimer, E., Walichnowski, A. Z., et al. (2012). Integrated consensus genetic and physical maps of flax (Linum usitatissimum L.). Theor. Appl. Genet. 125, 1783-1795. doi: 10.1007/s00122-012-1953-0

Cloutier, S., Ragupathy, R., Niu, Z., and Duguid, S. D. (2011). SSR-based linkage map of flax (Linum usitatissimum L.) and mapping of QTLs underlying fatty acid composition traits. Mol. Breed. 28, 437-451. doi: 10.1007/s11032-0109494-1

Cui, X., Liu, F., Liu, Y., Zhou, Z., Zhao, Y., Wang, C., et al. (2015). Construction of cytogenetic map of Gossypium herbaceum chromosome 1 and its integration with genetic maps. Mol. Cytogenet. 8, 2. doi: 10.1186/s13039-015-0106-y

Cullis, C. A. (2005). Mechanisms and control of rapid genomic changes in flax. Ann. Bot. 95, 201-206. doi: 10.1093/aob/mci013

Danilova, T. V., Friebe, B., and Gill, B. S. (2014). Development of a wheat single gene FISH map for analyzing homoeologous relationship and chromosomal rearrangements within the Triticeae. Theor. Appl. Genet. 127, 715-730. doi: $10.1007 / \mathrm{s} 00122-013-2253-\mathrm{z}$

Delmer, D. P. (1999). Cellulose biosynthesis: exciting times for a difficult field of study. Ann. Rev. Plant Physiol. Plant Mol. Biol. 50, 245-276.

Doblin, M. S., Kurek, I., Jacob-Wilk, D., and Delmer, D. P. (2002). Cellulose biosynthesis in plants: from genes to rosettes. Plant Cell Physiol. 43, 1407-1420.

Goldsbrough, P. B., and Cullis, C. A. (1981). Characterisation of the genes for ribosomal RNA in flax. Nucleic Acids Res. 9, 1301-1309.

Goldsbrough, P. B., Ellis, T. H., and Lomonossoff, G. P. (1982). Sequence variation and methylation of the flax 5S RNA genes. Nucleic Acids Res. 10, 4501-4514.

Gonzalez, V. M., Garcia-Mas, J., Arus, P., and Puigdomenech, P. (2010). Generation of a BAC-based physical map of the melon genome. BMC Genomics 11:339. doi: 10.1186/1471-2164-11-339

Gorshkova, T. A., Ageeva, M., Chemikosova, S., and Salnikov, V. (2005). Tissuespecific processes during cell wall formation in flax fiber. Plant Biosyst. 139, 88-92. doi: 10.1080/11263500500056070

Grushetskaya, Z. E., Lemesh, V. A., and Khotyleva, L. V. (2010). Development of specific and degenerate primers for CesA genes encoding cellulose synthase in flax (Linum usitatissimum L.). Cytol. Genet. 44, 195-199. doi: 10.3103/ S0095452710040018

Hardigan, M. A., Crisovan, E., Hamilton, J. P., Kim, J., Laimbeer, P., Leisner, C. P., et al. (2016). Genome reduction uncovers a large dispensable genome of fundamental research for state academies for 2013-2020 years (Task 0103-2014-0008 Subprogram No. 53 General genetics).

\section{ACKNOWLEDGMENTS}

The authors thank All-Russian Flax Institute, Torzok, Russian Federation for providing seeds of L. usitatissimum. The authors gratefully acknowledge Dr. Sylvie Cloutier (Cereal Research Centre, Agriculture and Agri-Food, Canada) for providing data on primer sequences.

and adaptive role for copy number variation in asexually propagated Solanum tuberosum. Plant Cell 28, 388-405. doi: 10.1105/tpc.15.00538

Holland, N., Holland, D., Helentjaris, T., Dhugga, K. S., Xoconostle-Cazares, B., and Delmer, D. P. (2000). A comparative analysis of the plant cellulose synthase (CesA) gene family. Plant Physiol. 123, 1313-1323. doi: 10.1104/pp.123. 4.1313

Iovene, M., Zhang, T., Lou, Q., Buell, C. R., and Jiang, J. (2013). Copy number variation in potato-an asexually propagated autotetraploid species. Plant J. 75, 80-89. doi: 10.1111/tpj.12200

Jiang, J., and Gill, B. S. (2006). Current status and the future of fluorescence in situ hybridization (FISH) in plant genome research. Genome 49, 1057-1068. doi: 10.1139/g06-076

Karafiátová, M., Bartoš, J., Kopecký, D., Ma, L., Sato, K., Houben, A., et al. (2013). Mapping nonrecombining regions in barley using multicolor FISH. Chromosome Res. 21, 739-751. doi: 10.1007/s10577-013-9380-x

Kaur, S., Dhugga, K. S., Gill, K., and Singh, J. (2016). Novel structural and functional motifs in cellulose synthase (CesA) genes of bread wheat (Triticum aestivum L.). PLoS ONE 11:e0147046. doi: 10.1371/journal.pone.0147046

Kawagoe, Y., and Delmer, D. P. (1997). Pathways and genes involved in cellulose biosynthesis. Genet. Eng. 19, 63-87.

Kirov, I., Van Laere, K., De Riek, J., De Keyser, E., Van Roy, N., and Khrustaleva, L. (2014). Anchoring linkage groups of the Rosa genetic map to physical chromosomes with Tyramide-FISH and EST-SNP markers. PLoS ONE 9:e95793. doi: 10.1371/journal.pone.0095793

Kirov, I., Van Laere, K., Van Roy, N., and Khrustaleva, L. (2016). Towards a FISH-based karyotype of Rosa L. (Rosaceae). Comp. Cytogenet. 10, 543-554. doi: 10.3897/CompCytogen.v10i4.9536

Kumar, M., and Turner, S. (2015). Plant cellulose synthesis: CESA proteins crossing kingdoms. Phytochemistry 112, 91-99. doi: 10.1016/j.phytochem.2014.07.009

Kumar, S., You, F. M., Duguid, S. D., Booker, H. M., Rowland, G. G., and Cloutier, S. (2015). QTL for fatty acid composition and yield in linseed (Linum usitatissimum L.). Theor. Appl. Genet. 128, 965-984. doi: 10.1007/s00122-0152483-3

Lamb, J. C., Danilova, T., Bauer, M. J., Meyer, J. M., Holland, J. J., Jensen, M. D., et al. (2007). Single-gene detection and karyotyping using small-target fluorescence in situ hybridization on maize somatic chromosomes. Genetics 175, 1047-1058. doi: 10.1534/genetics.106.065573

Liang, X., and Joshi, C. (2004). Molecular cloning of ten distinct hypervariable regions from the cellulose synthase gene superfamily in aspen trees. Tree Physiol. 24, 543-550. doi: 10.1093/treephys/24.5.543

Mokshina, N., Gorshkova, T., and Deyholos, M. K. (2014). Chitinase-like (CTL) and cellulose synthase (CESA) gene expression in gelatinous-type cellulosic walls of flax (Linum usitatissimum L.) bast fibers. PLoS ONE 9:e97949. doi: 10.1371/journal.pone.0097949

Muravenko, O. V., Lemesh, V. A., Samatadze, T. E., Amosova, A. V., Grushetskaia, Z. E., Popov, K. V., et al. (2003). Genome comparisons with chromosomal and molecular markers for three closely related flax species and their hybrids. Russ. J. Genet. 39, 414-421. doi: 10.1023/A:1023309831454

Muravenko, O. V., Yurkevich, O. Y., Bolsheva, N. L., Samatadze, T. E., Nosova, I. V., Zelenina, D. A., et al. (2009). Comparison of genomes of eight species of sections Linum and Adenolinum from the genus Linum based on chromosome banding, molecular markers and RAPD analysis. Genetica 135, 245-255. doi: 10.1007/s10709-008-9273-7 
Oh, T. J., and Cullis, C. A. (2003). Labile DNA sequences in flax identified by combined sample representational difference analysis (csRDA). Plant Mol. Biol. 52, 527-536. doi: 10.1023/A:1024838617817

Oh, T. J., Gorman, M., and Cullis, C. A. (2000). RFLP and RAPD mapping in flax (Linum usitatissimum). Theor. Appl. Genet. 101, 590-593. doi: 10.1007/ s001220051520

Popov, K. V., Muravenko, O. V., Samatadze, T. E., Amosova, A. V., and Zelenin, A. V. (2001). Peculiarities of studying the heterochromatic regions of small plant chromosomes. Dokl. Biol. Sci. 381, 543-546.

Rachinskaya, O. A., Lemesh, V. A., Muravenko, O. V., Yurkevich, O. Y., Guzenko, E. V., Bolsheva, N. L., et al. (2011). Genetic polymorphism of flax Linum usitatissimum based on use of molecular cytogenetic markers. Russ. J. Genet. 47, 56-65. doi: 10.1134/S1022795411010108

Ragupathy, R., Rathinavelu, R., and Cloutier, S. (2011). Physical mapping and BAC-end sequence analysis provide initial insights into the flax (Linum usitatissimum L.) genome. BMC Genomics 12:217. doi: 10.1186/1471-2164$12-217$

Ranik, M., and Myburg, A. (2006). Six new cellulose synthase genes from Eucalyptus are associated with primary and secondary cell wall biosynthesis. Tree Physiol. 26, 545-556. doi: 10.1093/treephys/26.5.545

Richmond, T. (2000). Higher plant cellulose synthases. Genome Biol. 1:REVIEWS3001. doi: 10.1186/gb-2000-1-4-reviews3001

Richmond, T., and Somerville, C. R. (2000). The cellulose synthase superfamily. Plant Physiol. 124, 495-498. doi: 10.1104/pp.124.2.495

Robert, S., Mouille, G., and Hofte, H. (2004). The mechanism and regulation of cellulose synthesis in primary walls: lessons from cellulose-deficient Arabidopsis mutants. Cellulose 11, 351-364. doi: 10.1023/B:CELL.0000046415.45774.80

Saxena, I. M., and Brown, R. M. Jr. (2005). Cellulose biosynthesis: current views and evolving concepts. Ann. Bot. 96, 9-21. doi: 10.1093/aob/mci155

Saxena, I. M., Brown, R. M., and Dandekar, T. (2001). Structure-function characterization of cellulose synthase: relationship to other glycosyltransferases. Phytochemistry 57, 1135-1148.

Scalabrin, S., Troggio, M., Moroldo, M., Pindo, M., Felice, N., Coppola, G., et al. (2010). Physical mapping in highly heterozygous genomes: a physical contig map of the Pinot Noir grapevine cultivar. BMC Genomics 11:204. doi: 10.1186/ 1471-2164-11-204
Schneeberger, R. G., Creissen, G. P., and Cullis, C. A. (1989). Chromosomal and molecular analysis of $5 \mathrm{~S}$ RNA gene organization in the flax, Linum usitatissimum. Gene 83, 75-84.

Swanson-Wagner, R. A., Eichten, S. R., Kumari, S., Tiffin, P., Stein, J. C., Ware, D., et al. (2010). Pervasive gene content variation and copy number variation in maize and its undomesticated progenitor. Genome Res. 20, 1689-1699. doi: $10.1101 /$ gr.109165.110

Taylor, N. G., Gardiner, J. C., Whiteman, R., and Turner, S. R. (2004). Cellulose synthesis in the Arabidopsis secondary cell wall. Cellulose 11, 329-338. doi: 10.1023/B:CELL.0000046405.11326.a8

Wang, L., Guo, K., Li, Y., Tu, Y., Hu, H., Wang, B., et al. (2010). Expression profiling and integrative analysis of the CESA/CSL superfamily in rice. BMC Plant Biol. 10:282. doi: 10.1186/1471-2229-10-282

Wang, Z., Hobson, N., Galindo, L., Zhu, S., Shi, D., McDill, J., et al. (2012). The genome of flax (Linum usitatissimum) assembled de novo from short shotgun sequence reads. Plant J. 72, 461-473. doi: 10.1111/j.1365-313X.2012.05093.x

Wei, F., Zhang, J., Zhou, S., He, R., Schaeffer, M., Collura, K., et al. (2009). The physical and genetic framework of the maize B73 genome. PLoS Genet. 5:e1000715. doi: 10.1371/journal.pgen.1000715

Yurkevich, O. Y., Naumenko-Svetlova, A. A., Bolsheva, N. L., Samatadze, T. E., Rachinskaya, O. A., Kudryavtseva, A. V., et al. (2013). Investigation of genome polymorphism and seed coat anatomy of species of section Adenolinum from the genus Linum. Genet. Resour. Crop Evol. 60, 661-676. doi: 10.1007/s10722012-9865-z

Conflict of Interest Statement: The authors declare that the research was conducted in the absence of any commercial or financial relationships that could be construed as a potential conflict of interest.

Copyright (c) 2017 Yurkevich, Kirov, Bolsheva, Rachinskaya, Grushetskaya, Zoschuk, Samatadze, Bogdanova, Lemesh, Amosova and Muravenko. This is an open-access article distributed under the terms of the Creative Commons Attribution License (CC BY). The use, distribution or reproduction in other forums is permitted, provided the original author(s) or licensor are credited and that the original publication in this journal is cited, in accordance with accepted academic practice. No use, distribution or reproduction is permitted which does not comply with these terms. 